\title{
Structural and dielectric properties of some epiclon-based polyimide films
}

\author{
Andreea Irina Cosutchi, ${ }^{1}$ Camelia Hulubei, ${ }^{1}$ Iuliana Stoica, ${ }^{1}$ Marius Dobromir, ${ }^{2}$ Silvia \\ $\operatorname{loan}^{1 *}$ \\ $1^{*}$ "Petru Poni" Institute of Macromolecular Chemistry, Aleea Grigore Ghica Voda 41A, \\ 700487 - lasi, Romania; Fax: +40 232211 299; e-mail: ioan_silvia@yahoo.com \\ 2 "Al. I. Cuza" University, Faculty of Physics, Blvd. Carol I 11, 700506-lasi, Romania; \\ fax: +40 232201 150; e-mail: mdobromir@uaic.ro
}

(Received: 8 February, 2008; published: 28 May, 2008)

\begin{abstract}
Surface and electrical properties of two flexible and cross-linked epiclon based polyimide films were investigated. Surface tension measurements indicate an increased hydrophobicity due to both isothermal treatment - which induces imidization and cross-linking - and to the chemical structure, characterized by the different number of ether linkages in the polyimide backbone. Morphology of film surfaces, modified by plasma treatment, shows high roughness and, implicitly, improved adhesion, as required in electronics. The studied polyimides exhibit low dielectric constants and dielectric losses, comparatively to conventional aromatic polyimides. The electrical conductance and resistivity characteristics of these polymers recommend them as good insulators for dielectric layers in microelectronic applications.
\end{abstract}

\section{Introduction}

Polyimides represent a special class of polymers which, due to their outstanding thermal, mechanical and electrical properties, have found widespread applicability, from microelectronics to aerospace industry [1-4]. They differ from other high performance polymers by the solubility of their poly(amic acid) precursor form, which can be cast into uniform films and quantitatively converted to polyimide [5].

The increasing importance of polyimides in the manufacturing of integrated circuits has motivated numerous investigations devoted to dielectric materials [6-9]. Of utmost importance in microelectronic applications is the low value of the dielectric constant, the low interfacial stress, the good adhesion to the substrate and the reduced moisture absorption. In electronic packing, the low dielectric materials minimize cross talk and maximize signal propagation speed in devices. Literature describes different strategies for dielectric constant reduction, such as: (1) incorporation of diamine and dianhydride reactants, which minimize polarizability, (2) incorporation of diamine and dianhydride reactants, which impart a high degree of free volume, and (3) incorporation of specific atoms into the molecular structure of the polyimide, which lower moisture absorption [5]. According to Yamazaki et al., cross-linking in a polyimide may lead to a porous structure, giving films with a low dielectric constant [10].

However, conventional polyimides, which are wholly aromatic, although thermally stable, do not always provide the optimum properties for many specialty applications, due to some deficiencies in processability, solubility, and transparency, and to their 
relatively high dielectric constant. Poor thermoplastic fluidity and solubility are the major problems in the application of conventional polyimides [11], which renders their processing difficult and considerably restricts their commercial uses. Various attempts have been made at overcoming these deficiencies, including the use of non-coplanar monomers and the introduction of flexible segments into the polymer backbone [12-15]. Such strategies aim at reducing chain crystallinity, the intermolecular charge-transfer and the electronic polarization interactions. An alternative, successful approach involves incorporation of pendant groups into the rigid polyimide backbone [13]. These works have shown that the presence of bulky groups could effectively prevent the coplanarity of aromatic rings and reduce the packing efficiency of the molecular chains, without affecting the thermal properties.

Incorporation of aliphatic or cycloaliphatic monomers to form partially aliphatic polyimides has been used to counteract some of the shortcomings of the wholly aromatic polyimides $[16,17]$. Compared to conventional polyimides, the partially aliphatic ones offer an unique combination of qualities, such as: lower dielectric constant, good transparency and higher flexibility and, implicitly, better processability. Introduction of an aliphatic unit into the polyimide backbone would facilitate fewer polymer-polymer interactions and enhance solubility in organic solvents [18]. Also, the combination of imide units, aromatic rings, flexible bonds and epiclon (5- $(2,5-$ dioxotetrahydrofurfuryl)-3-methyl-3-cyclohexene-1,2-dicarboxylic acid anhydride) moieties in the same macromolecule would yield new polyimides, providing a compromise between processability, on one side, and the physical and thermal characteristics, on the other [19, 20].

In previous papers, the conformational characterization in dilute solution [21], the hydrophobicity/hydrophilicity balance, the surface free energy [22] and the electrical properties [23,24] of some epiclon-based polyimides were studied versus their corresponding poly(amic acid)s. In this work, novel cross-linked partial aliphatic polyimides based on epiclon have been prepared by thermal imidization of the corresponding poly(amic acid)s, and the influence of the chemical structure on the electrical and surface properties of these compounds has been evaluated.

\section{Results and discussion}

Most electronic applications require specific characteristics, such as wetting and roughness, for granting good adhesion, refractivity, absorption and insulation characteristics. The effects of the structural modifications induced by the two different diamines and by thermal imidization, respectively, on the surface and dielectric properties, were investigated as to the suitability of these compounds for microelectronic applications.

\section{Surface tension properties}

The methods used for the determination of surface tensions are based on contact angle measurements between the liquid meniscus and the polymer surface. Table 1 lists the contact angles between polyimide films and double-distilled water, 1-bromnaphthalene and formamide.

The experimental data for the surface tension components were obtained by the geometric mean method (GM) (Eqs. (1)-(3)) [25-27], as well as by the acid/base method (LW/AB) (Eqs. (4)-(7)) [28-30]: 
Tab. 1. Contact angle of different liquids for polyimide films, in $\left(^{\circ}\right)$.

\begin{tabular}{lcc}
\hline Liquid test & \multicolumn{2}{c}{ Contact angle } \\
\cline { 2 - 3 } & $\mathrm{PI} 1$ & $\mathrm{PI} 2$ \\
\hline Water & 58 & 67 \\
1-Brom-naphthalene & 20 & 15 \\
Formamide & 46 & 38 \\
\hline
\end{tabular}

$$
\begin{aligned}
& \frac{1+\cos \theta}{2} \cdot \frac{\gamma_{I V}}{\sqrt{\gamma_{I V}^{d}}}=\sqrt{\gamma_{S V}^{p}} \cdot \sqrt{\frac{\gamma_{I V}^{p}}{\gamma_{I V}^{d}}}+\sqrt{\gamma_{S V}^{d}} \\
& \gamma_{S V}=\gamma_{S V}^{d}+\gamma_{S V}^{p} \\
& \gamma_{S I}=\left(\sqrt{\gamma_{I V}^{p}}-\sqrt{\gamma_{S V}^{p}}\right)^{2}+\left(\sqrt{\gamma_{I V}^{d}}-\sqrt{\gamma_{S V}^{d}}\right)^{2}
\end{aligned}
$$

where $\theta$ is the contact angle determined for three liquids, subscripts " $l v$ ", "sv" and "sl" denote the liquid-vapor, surface-vapor and solid-liquid interfacial tensions, respectively, while superscripts " $p$ " and " $d$ " denote the polar and the disperse components, respectively, of the total surface tension, $\gamma_{s v}$.

$$
\begin{aligned}
& 1+\cos \theta=\frac{2}{\gamma_{I V}} \cdot\left(\sqrt{\gamma_{s V}^{d} \cdot \gamma_{I V}^{d}}+\sqrt{\gamma_{S V}^{+} \cdot \gamma_{I V}^{-}}+\sqrt{\gamma_{s V}^{-} \cdot \gamma_{I V}^{+}}\right) \\
& \gamma_{S V}^{p}=2 \cdot \sqrt{\gamma_{s V}^{+} \cdot \gamma_{s V}^{-}} \\
& \gamma_{s V}=\gamma_{s V}^{d}+\gamma_{S V}^{p} \\
& \gamma_{s l}=\left(\sqrt{\gamma_{s V}^{d}}-\sqrt{\gamma_{I V}^{d}}\right)^{2}+2\left(\sqrt{\gamma_{S V}^{+} \gamma_{s V}^{-}}+\sqrt{\gamma_{I V}^{+} \gamma_{I V}^{-}}-\sqrt{\gamma_{s V}^{+} \gamma_{I V}^{-}}-\sqrt{\gamma_{s V}^{-} \gamma_{I V}^{+}}\right)
\end{aligned}
$$

where $\gamma_{s v}^{-}$and $\gamma_{s v}^{+}$represent the electron-donor and electron-acceptor interactions, respectively.

According to the geometric mean method, $\gamma_{S V}^{p}$ and $\gamma_{S V}^{d}$ were determined from the slope and intercept of the linear fit to the data, according to Eq. (1), on using the contact angle of at least three liquids. As to Eq. (4) (the acid/base method), literature data indicate that three polar liquids and a set of three equations may be used, if the values of the liquids parameters, such as $\gamma_{s v}^{-}$or $\gamma_{s v}^{+}$, are not too close [31,32]. Della Volpe et al. [33] show that an improper utilization of the three liquids, without dispersive liquids, or with two prevalently basic or prevalently acidic liquids strongly increases the ill-conditioning of the system. The different estimates of the acid-base components, obtainable for the same solid by different triplets of liquids, do not necessarily imply that this method is inconsistent, but may simply reflect the large inaccuracies affecting the results, as due to ill-conditioning. Also, literature postulated [34] that contact angles should be measured with a liquid of surface tension higher than the anticipated solid surface tension, i.e., $\gamma_{/ V}>\gamma_{S V}$. Eq. (4), written for three liquids, leads to a three equation system for determining the surface tension components. In our investigation, this system was simplified to two equations, because, according to Table 2, 1-bromo-naphthalene is an apolar solvent. Table 3 
shows the results for the surface tension components evaluated with both methods. The electron-donor and electron-acceptor parameters obtained by the acid/base method were also presented.

Tab. 2. Surface tension components and electron-donor and electron-acceptor parameters $(\mathrm{mN} / \mathrm{m})$ of the liquids used for contact angle measurements.

\begin{tabular}{lcccrr}
\hline \multicolumn{1}{c}{ Test liquid } & $\gamma_{I V}$ & $\gamma_{I V}^{d}$ & $\gamma_{I V}^{p}$ & \multicolumn{1}{c}{$\gamma_{I V}^{-}$} & \multicolumn{1}{c}{$\gamma_{I V}^{+}$} \\
\hline Water [35] & 72.80 & 21.80 & 51.00 & 25.50 & 25.50 \\
Formamide [36] & 58.00 & 39.00 & 19.00 & 39.60 & 2.28 \\
1-brom-naphthalene [37] & 44.40 & 44.40 & 0 & 0 & 0 \\
\hline
\end{tabular}

Tab. 3. Surface tension components $(\mathrm{mN} / \mathrm{m})$ obtained by the geometric mean method (Eqs. (1)-(3)), and the acid/base method (Eqs. (4)-(6)), with the corresponding electron-donor and electron-acceptor parameters $(\mathrm{mN} / \mathrm{m})$.

\begin{tabular}{ccccccccc}
\hline Sample & \multicolumn{3}{c}{ GM method } & \multicolumn{5}{c}{ Acid/base method } \\
\cline { 2 - 9 } & $\gamma_{S V}^{d}$ & $\gamma_{S V}^{p}$ & $\gamma_{s V}$ & $\gamma_{S V}^{d}$ & $\gamma_{s V}^{-}$ & $\gamma_{S V}^{+}$ & $\gamma_{S V}^{p}$ & $\gamma_{s V}$ \\
\hline PI1 & 34.53 & 12.79 & 47.32 & 37.31 & 22.75 & 0.36 & 5.72 & 43.03 \\
PI2 & 38.83 & 7.71 & 46.55 & 44.58 & 12.66 & 0.08 & 2.05 & 46.63 \\
\hline
\end{tabular}

Previous data [22] show that the absence or presence of methylene groups, and the number of aromatic rings in the structural unit of polyimides based on epiclon do not essentially modify hydrophobicity, comparatively with the ether linkages, which leads to a lower polar component. The maximal hydrophobicity of the polyimides with ether linkages would be advantageous for dielectric performance, since the absorbed water causes a significant increase in the dielectric constant and, implicitly, considerable degradation of the adhesion to different inorganic interfaces in electronic packaging. The thermal treatment of the poly(amic acid) precursors, corresponding to polyimides PI1 and PI2, additionally leads to cross-linking, as due to the special structure of epiclon, which assures stabilization, known as essential for obtaining flexible films. Thus, surface tension measurements indicated reorganization of the hydrophobic groups on the polyimide surface after cross-linking (Table 3), comparatively with the samples not subjected to any isothermal imidization treatment [22].

The effects of the chemical structure and surface properties on polyimide applications can be evaluated from the interfacial tension $\gamma_{s l}$ (Eq. (3) or Eq. (7)) between the polymer film and water, and also from the surface free energy, $\Delta G_{W}$, expressing the balance between surface hydrophilicity and hydrophobicity (Table 4). The $\Delta G_{w}$ values were obtained [38] from Eq. (8), with the total surface tension parameter of water $-\gamma_{I V}$, from Table 2, and water-sample contact angle, $\theta_{\text {water }}$ from Table 1.

$\Delta G_{W}=-\gamma_{I V} \cdot\left(1+\cos \theta_{\text {water }}\right)$

Generally, the literature $[30,38]$ mentions that, for $\Delta G_{W}<-113 \mathrm{~mJ} / \mathrm{m}^{2}$, the polymer can be considered more hydrophilic while, when $\Delta G_{w}>-113 \mathrm{~mJ} / \mathrm{m}^{2}$, it should be considered more hydrophobic. Thus, the polymer film-water interfacial tensions, $\gamma_{s l}$, 
and the surface free energy, $\Delta G_{w}$, evidence the low wettability of the studied polyimides.

Tab. 4. Solid-water interfacial tensions from $G M$ and acid/base methods, and the surface free energy of hydration.

\begin{tabular}{llll}
\hline Sample & $\gamma_{s l}$ & $\gamma_{s l}$ & $\Delta G_{W}$ \\
& $($ Eq. (3)) & $($ Eq. $(7))$ & \\
\hline PI1 & 14.19 & 4.56 & -111.38 \\
PI2 & 21.53 & 18.22 & -106.94 \\
\hline
\end{tabular}

Surface morphology

Atomic force microscopy (AFM) was used to examine the film surface and to measure its surface topography. Figures 1 and 2 plots the bi- and three-dimensional structure, respectively.
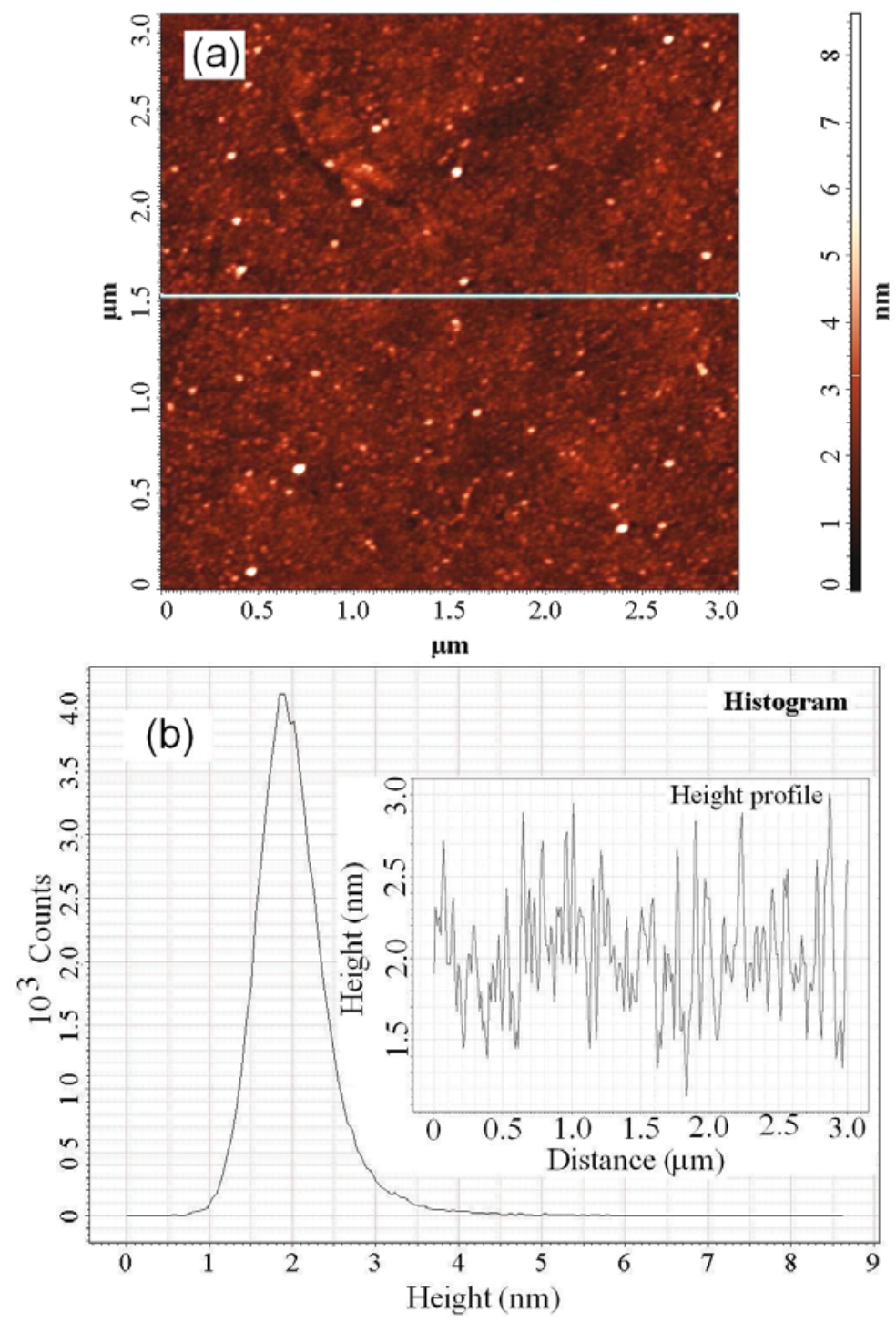

Fig. 1. 2D-AFM image for: (a) - untreated PI1 film; (b) - histogram and surface profile taken along the line in Figure $1 \mathrm{a}$ (small plot). 
The film surface is covered with submicrometer-scaled granules. When the film is examined at nanoscale, the surface shows a root-mean-square $(\mathrm{rms})$ roughness of the $0.505 \mathrm{~nm}$ order, over an area of $3 \times 3 \mu \mathrm{m}^{2}$. Height profile analysis (the small plot from Figure 1b) along the horizontal line from Figure 1a characterizes the topography of the surface and measures an average height of $2 \mathrm{~nm}$ (Figure 1b). The surface morphology and roughness of the polyimide film derive mainly from the characteristics of the polymer chains that govern aggregation and molecular ordering, which occur during drying and thermal imidization processes.

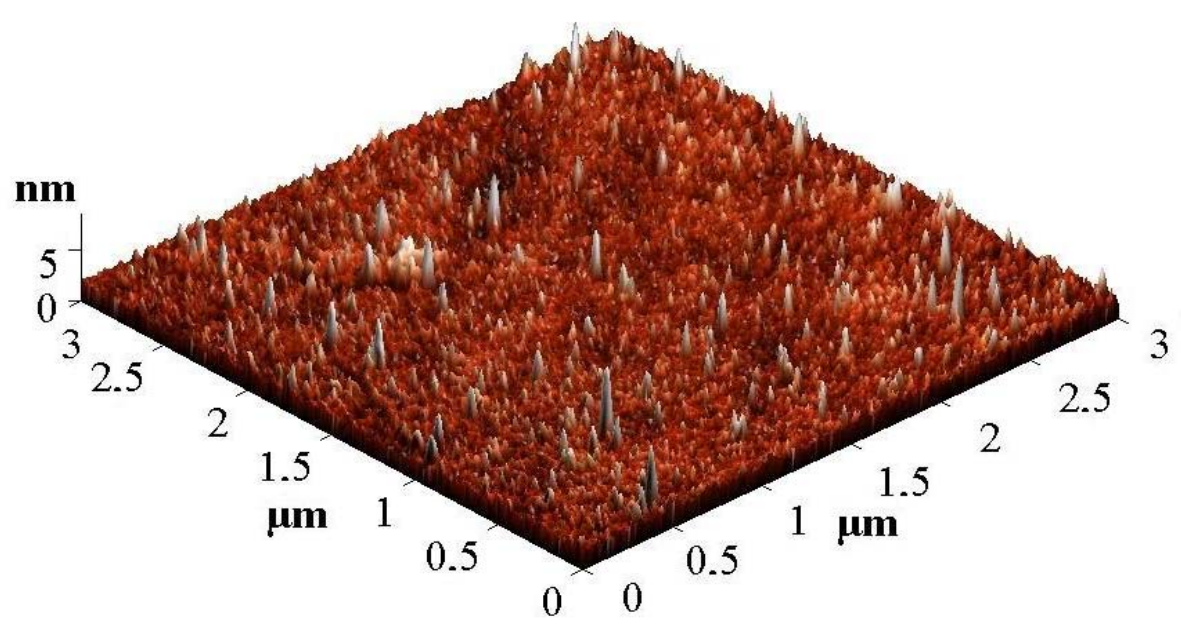

Fig. 2. 3D-AFM image for the untreated PI1 film.

The plasma treatment effect of the PI1 film, illustrated by AFM images (Figures 3 and 4 ) and the surface profile (Figure $3 b$ ), shows modification in surface topography, reflected by a higher rms roughness of the $5.105 \mathrm{~nm}$ order. According to previous data [22], the plasma treatment decreases hydrophobicity, yet the effect is reversible after 10 days.

Also, Figures $3 a$ and $b$ reveal that the plasma treatment damages the polymer surface, generating chemical defects and modification of the morphological structures. Thus, plasma intensifies roughness, a phenomenon which remains constant in time, so that granule height, shown in height profile, increases from $3 \mathrm{~nm}$ to $30 \mathrm{~nm}$, or, as plotted in the histogram, the average height increases from $2 \mathrm{~nm}$ to $20 \mathrm{~nm}$ (Figures 2 and 4).

Roughness is also discernible for the PI2 film in Figures 5 and 6 . The figures show that the rms surface roughness is of the $2.037 \mathrm{~nm}$ order, and also that the plasmatreated sample increases this parameter up to $9.623 \mathrm{~nm}$, thus modifying the height profile and average height from 12 to $45 \mathrm{~nm}$, and from 6 to $25 \mathrm{~nm}$, respectively.

AFM studies support the conclusion that enhancement in roughness is generated by a structural peculiarity of the polyimides obtained by introducing different diamine structures in the synthesis, and by plasma treatment, as well. Thus, an increasing number of ether linkages in the vicinity of the phenylenic units increases roughness and, implicitly, determines better adhesion of the polyimide films. 

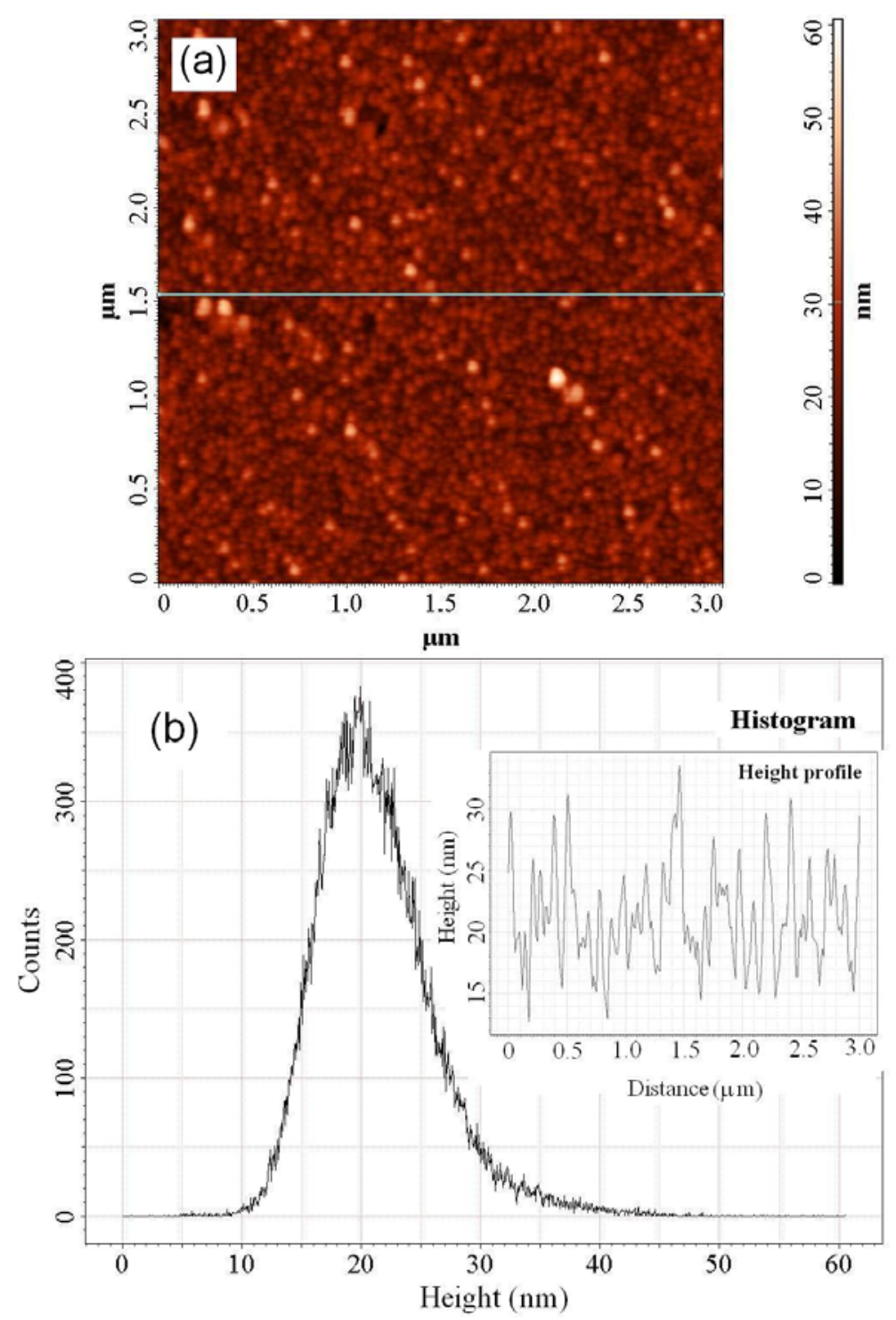

Fig. 3. 2D-AFM image for: (a) - plasma treated PI1 film; (b) - histogram and surface profile taken along the line in Figure $3 a$ (small plot).

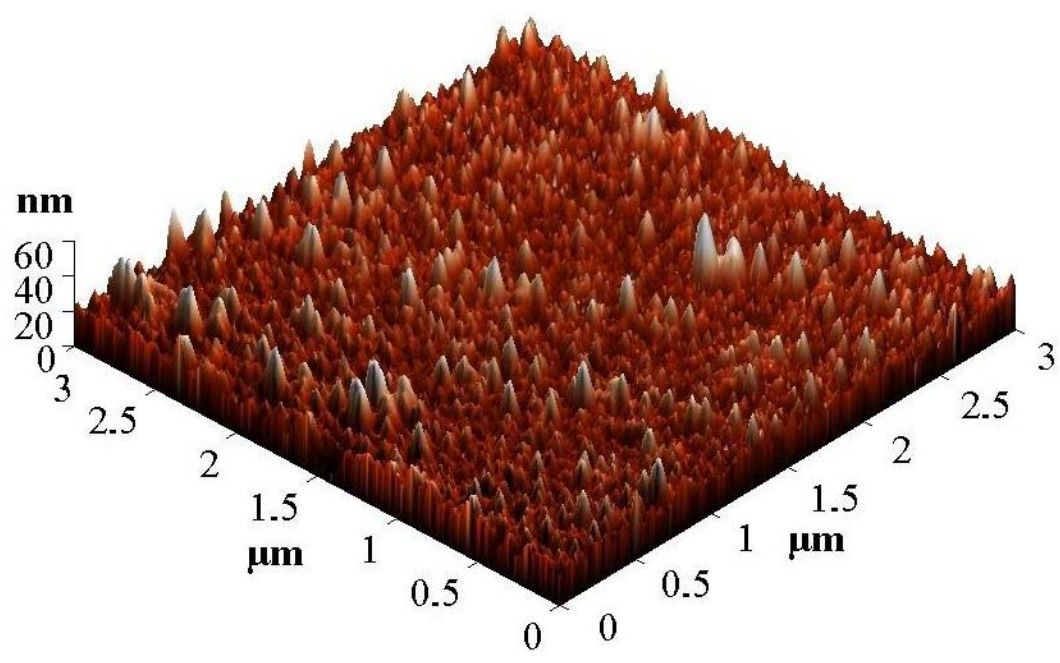

Fig. 4. 3D-AFM image for the plasma treated PI1 film. 

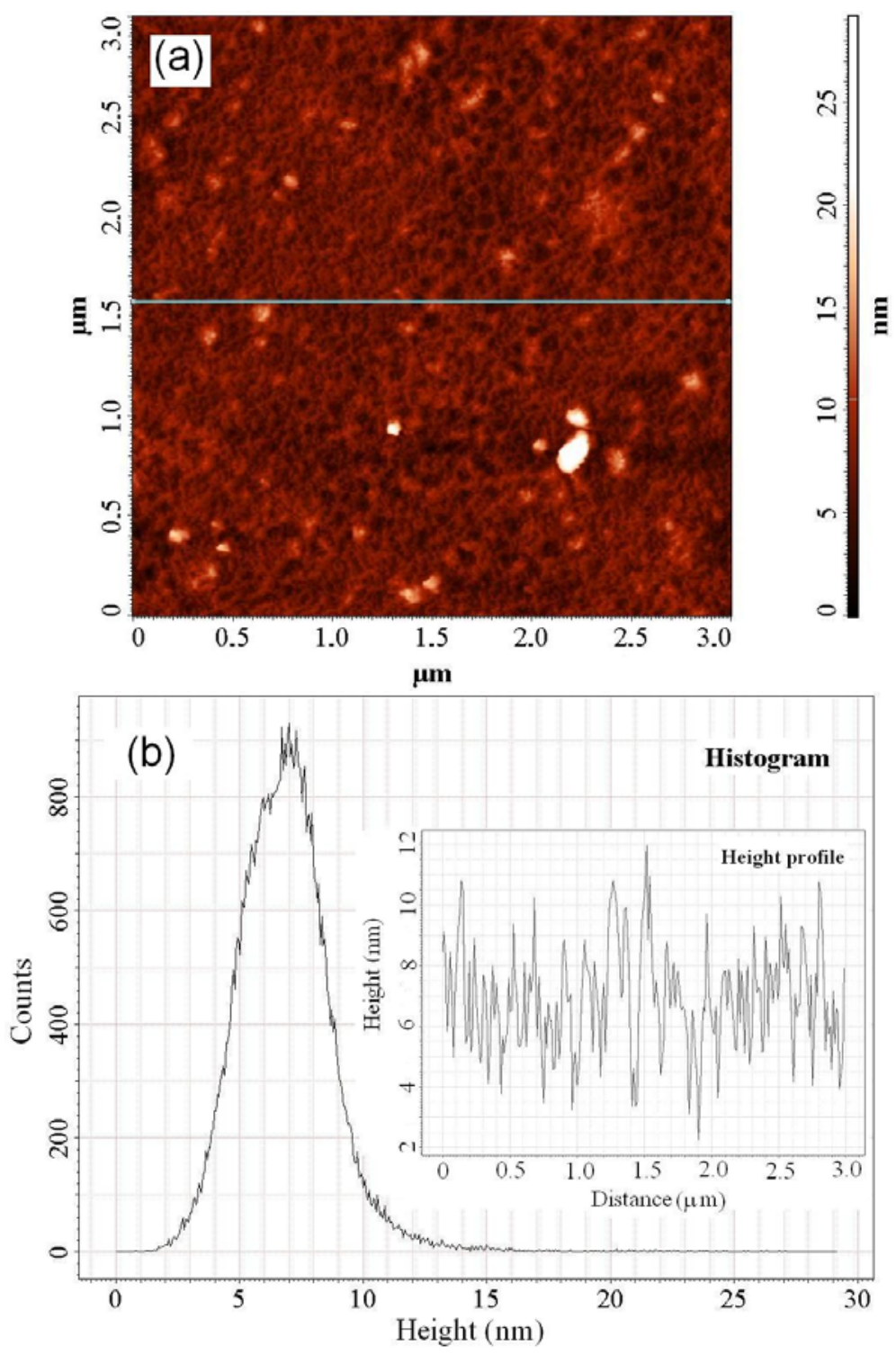

Fig. 5. 2D-AFM image for: (a) - untreated PI2 film; (b) - histogram and surface profile taken along the line in the Figure $5 a$ (small plot).

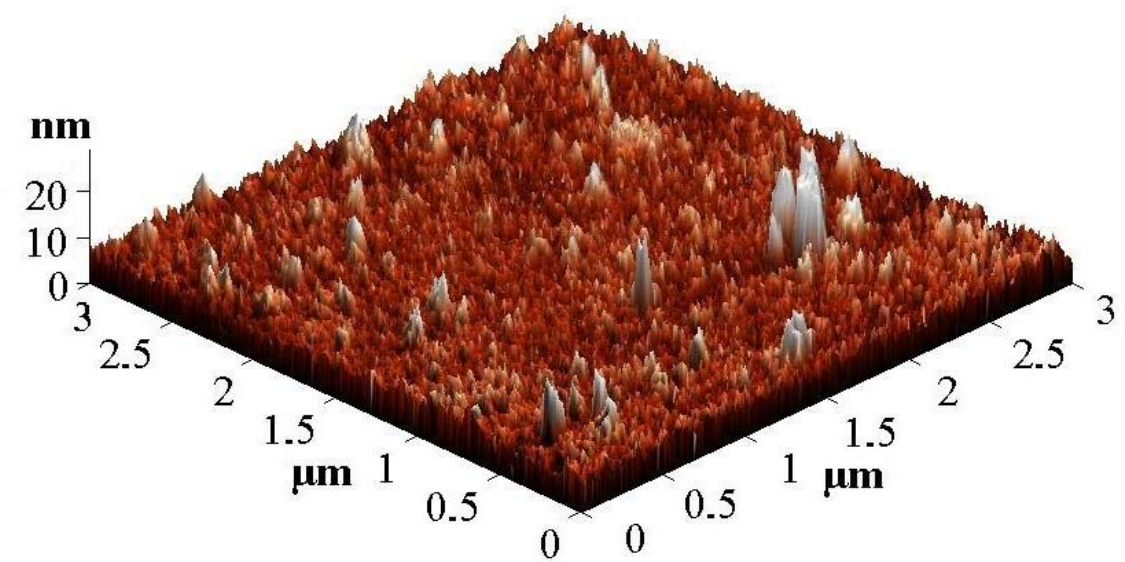

Fig. 6. 3D-AFM image for the untreated PI2 film. 


\section{Ellipsometry data}

The dependence of the ellipsometric parameters $\Psi$ and $\Delta$ on the incidence angle $\alpha$ is important for establishing a correct mathematical relationship for the determination of the optical constants (Eqs. (9) and (10)).

$$
\begin{aligned}
& n_{2}^{\prime}=n_{1} \tan \alpha\left[1-\frac{4 \cdot \rho}{(1+\rho)^{2}} \cdot \tan ^{2} \alpha\right]^{1 / 2} \\
& \rho=\tan \Psi \cdot e^{i \Delta}
\end{aligned}
$$

where $n_{1}$ is the refractive index of the air and $n_{2}^{\prime}$ is the complex refractive index, related to the refractive index of the polymer, $n_{2}$, and to the extinction coefficient, $k_{2}$ (Eq. (11)).

$$
n_{2}^{\prime}=n_{2}-i k_{2}
$$

The $\Psi$ and $\Delta$ measured values and the optical constants $n_{2}$ and $k_{2}$ are listed in Table 5.

Tab. 5. Ellipsometric parameters measured at different incidence angles, the refractive index and the surface extinction coefficient for PI1 and PI2 films.

\begin{tabular}{ccccccccc}
\hline$\alpha$ & \multicolumn{4}{c}{ PI1 film } & \multicolumn{5}{c}{ PI2 film } \\
\cline { 2 - 9 } & $\Psi$ & $\Delta$ & $n_{2}$ & $k_{2}$ & $\Psi$ & $\Delta$ & $n_{2}$ & $k_{2}$ \\
\hline 85 & 19.273 & 0.728 & 1.615 & 0.097 & 28.611 & 3.222 & 1.612 & 0.123 \\
80 & 10.721 & 3.342 & 1.606 & 0.023 & 22.345 & 9.839 & 1.612 & 0.289 \\
75 & 4.358 & 4.241 & 1.611 & 0.064 & 13.291 & 13.177 & 1.619 & 0.106 \\
70 & 12.849 & 1.767 & 1.607 & 0.046 & 7.112 & 17.481 & 1.611 & 0.441 \\
65 & -1.628 & 2.7327 & 1.612 & 0.042 & 3.547 & 25.381 & 1.615 & 0.108 \\
60 & -0.330 & 11.730 & 1.613 & 0.074 & 1.479 & 51.707 & 1.613 & 0.652 \\
55 & 1.783 & 174.692 & 1.609 & 0.050 & 1.899 & 164.751 & 1.614 & 0.152 \\
50 & 6.619 & 178.362 & 1.618 & 0.026 & 6.593 & 174.225 & 1.612 & 0.092 \\
45 & 13.452 & 174.271 & 1.619 & 0.012 & 13.396 & 174.344 & 1.619 & 0.079 \\
\hline
\end{tabular}

Tab. 6. Capacitance and dipolar dielectric constant for PI1, PI2 and poly(amic acid) corresponding to the PI2 sample (PAA2).

\begin{tabular}{lccccccc}
\hline Samples & \multicolumn{3}{c}{$\mathrm{C}$ in pF } & & $\varepsilon_{\text {dipolar }}$ & $\begin{array}{c}\varepsilon_{\text {electronic }} \\
\text { Eq. (12) }\end{array}$ \\
\cline { 2 - 8 } & $1 \mathrm{kHz}$ & $10 \mathrm{kHz}$ & $100 \mathrm{kHz}$ & $1 \mathrm{kHz}$ & $10 \mathrm{kHz}$ & $100 \mathrm{kHz}$ & $10^{11} \mathrm{kHz}$ \\
\hline $\mathrm{PI} 1$ & 1.31 & 1.26 & 1.43 & 5.12 & 4.93 & 4.74 & 2.61 \\
PI2 & 2.85 & 2.80 & 2.78 & 3.22 & 3.19 & 3.14 & 2.59 \\
PAA2 [37] & 2.01 & 1.30 & 1.12 & 15.26 & 9.87 & 8.50 & 2.84 \\
\hline
\end{tabular}

The refractive indices are easily influenced by the diamine structures used in the synthesis, showing values corresponding to transparent materials, while the extinction coefficients show that the investigated samples exhibit small absorption. Also, the refractive indices obtained by this method agree with those obtained from theoretical evaluations, where $n_{2}=1.615$ for PI1 and $n_{2}=1.611$ for PI2 [23]. 
The refractive index allows evaluation of the dielectric constant in the visible domain, by Maxwell equation (12), according to Table 6.

$\varepsilon_{\text {electronic }}=n_{2}^{2}$

\section{Electrical properties}

The dielectric constants corresponding to the dipolar polarization, $\varepsilon_{\text {dipolar }}$, experimentally determined from the electrical capacitance values, over a frequency range between $1-100 \mathrm{kHz}$, according to Eq. (13), are also presented in Table 6:

$\varepsilon_{\text {dipolar }}=\frac{C \cdot d}{\varepsilon_{0} \cdot S}$

where $d$ and $S$ represent thickness and area of the sample, respectively, $C$ is electrical capacitance and $\varepsilon_{0}=8.854 \cdot 10^{-12} \mathrm{~F} / \mathrm{m}$ represents absolute permittivity.

Capacitance is constant at different electrical tensions, decreasing with increasing frequency. Also, the dielectric constant exhibits a small decrease with angular frequency, $\omega$, in both microwave and optical domains.

Another factor affecting the dielectric behavior of a material is its chemical structure, known as influencing charge distribution and motion of dipoles. Previous data [39] show that the dielectric constants obtained for poly(amic acid) precursors and from partially aliphatic epiclon-based polyimides are low, reflecting the influence of the different binding structures. Increase of the methylenic groups or the presence of ether linkages in the chemical structure of poly(amic acid)s and of their corresponding polyimides leads to a small decrease of the dielectric constants. For these samples, large differences were observed between the dielectric constants at low $(1 \mathrm{kHz})$ and high $\left(\sim 10^{14} \mathrm{~Hz}\right)$ frequencies, while with increasing the methylenic groups or in the presence of ether linkages, the extent of such variation decreased. On the other hand, Table 6 shows that cross-linking of epiclon-based polyimides leads to a small increase of the dielectric constant towards the low frequency region, comparatively with the poly(amic acid), a case in which a larger difference between the dielectric constant at high and low frequencies is observed. The small differences observed between the dielectric constants of PI1 and PI2 could be the result of a possible modification of the free volume, as induced by their different structure [4042]. Thus, according to FTIR analysis, the disappearance of amide and carboxyl absorptions indicates a virtually complete conversion of the poly(amic acid) precursor into the polyimide PI2, while PI1 revealed characteristic absorption bands of the imide ring together with two residual amide absorption bands. In the latter case, poly(amic acid) film might not be completely converted into imides, and the corresponding PI1 film could be slightly polar than PI2, leading to modification of dielectric constants.

To investigate how easily electricity flows along a certain path through the studied polymers, the dependencies between electrical conductance, $G$, and electrical tension were also studied over the $1-100 \mathrm{kHz}$ frequency domain. Electrical conductance takes values between $10^{-8}-10^{-10} \mathrm{~S}$, indicating that, according to Table 7 , the investigated polymers appear as dielectrics. 
Tab. 7. Electrical resistivity, electrical conductance and dielectric loss values of the studied polyimides.

\begin{tabular}{lccccccc}
\hline Samples & $\begin{array}{c}\rho \cdot 10^{-11} \\
\text { in } \Omega \mathrm{m}\end{array}$ & \multicolumn{3}{c}{$\mathrm{G} \cdot 10^{10} \mathrm{in} \mathrm{S}$} & \multicolumn{3}{c}{$\tan \delta$} \\
\cline { 3 - 7 } & & $1 \mathrm{kHz}$ & $10 \mathrm{kHz}$ & $100 \mathrm{kHz}$ & $1 \mathrm{kHz}$ & $10 \mathrm{kHz}$ & $100 \mathrm{kHz}$ \\
\hline $\mathrm{PI} 1$ & 1.875 & 1.20 & 18.0 & 210 & 0.015 & 0.023 & 0.023 \\
$\mathrm{PI} 2$ & $\begin{array}{c}\text { very good } \\
\text { insulator }\end{array}$ & 2.15 & 27.9 & 261 & 0.012 & 0.016 & 0.015 \\
& & & & & & & \\
\hline
\end{tabular}

To evaluate the rate of power loss in the form of heat, the dissipation factor $(\tan \delta)$ was calculated as:

$\tan \delta=\frac{G}{\omega \cdot C}$

where $\omega$ is the angular frequency.

Table 7, showing the dielectric loss dependence on angular frequency, over the 1$100 \mathrm{kHz}$ domain, allows the following observations:

- introduction of different diamines containing one or two ether linkages in the vicinity of the phenylenic units induces lower values of the dielectric loss;

- the dielectric losses of the PI1 and PI2 samples are slightly lower than those of the conventional polyimides with aromatic structure, described in literature [5];

- the dielectric loss increases as the logarithm of angular frequency increases, reaching a maximum at approx. 4.8 (value corresponding to frequency about of 7 $\mathrm{kHz}$ ), after which it slightly decreases. This conclusion, despite the few experimental data, is supported by literature [5] which shows a similar behavior for conventional aromatic polyimides at $21{ }^{\circ} \mathrm{C}$; for these polyimides, the maximum value of the dielectric loss was observed in range of $1-100 \mathrm{kHz}$ is 0.018 , at approx. $20 \mathrm{kHz}$. The maximum of $\tan \delta$ can be associated with the onset of cooperative mobility of the chain segments [43].

Apart from the dielectric properties, a high resistivity indicates a material that does not readily allows movement of the electrical charge. A classical example of a good dielectric property is that of glass, where $\rho=10^{10}-10^{14} \Omega \mathrm{m}$. For both studied polyimides, the resistivity values (Table 7) calculated from the current - voltage characteristics are high, corresponding to good dielectric polymers. In addition, it was observed that, for the PI2 film, the electric current intensity is close to zero, which recommends it as a very good insulator.

\section{Conclusions}

Two new cross-linked flexible polyimide films based on epiclon, prepared by thermal imidization of the corresponding poly(amic acid)s, have been studied by the contact angle method for their surface properties, atomic force microscopy and ellipsometry. Surface properties indicate a higher hydrophobicity in cross-linked polyimides, with increase in the number of ether linkages. 
AFM studies on surface morphology and topography revealed the presence of roughness, generated by the structural peculiarities of the samples, and intensified by plasma treatment.

Ellipsometry data show that the cross-linked polymers have low extinction coefficients and refractive indices corresponding to transparent materials, the latter ones being slightly influenced by the chemical structure of the used diamines. Both polymers present small dielectric constants, which slightly increase towards the low frequency region, so that the studied polyimide films can be considered as dielectric layers in the microelectronic industry. According to electrical resistivity measurements, the polymers become better insulators if the number of ether linkages increases.

\section{Experimental part}

\section{Polymer synthesis}

Epiclon (5-(2,5-dioxotetrahydrofurfuryl)-3-methyl-3-cyclohexene-1,2-dicarboxylic acid anhydride), an asymmetrical flexible alicyclic dianhydride (Merk, 98\% purity), has been used as a raw material for polyimides, to enhance their solubility and to render some new properties of theirs [44, 45]. The poly(amic acid) precursors were synthesized by the reaction of epiclon with 1,4- ( $p$-aminophenoxy)benzene (1) and 1,4-bis( $p$-aminophenoxy)benzene (2), respectively, in N-methylpyrrolidinone (NMP) as solvent, under inert atmosphere. Concentration of the reaction mixture was adjusted to $20 \%$ total solids. The reaction, performed at $15-20{ }^{\circ} \mathrm{C}$, led to the corresponding poly(amic acid)s. Polyimide films were prepared through imidization of poly(amic acid) films cast on a glass substrate, which was placed overnight in an $80^{\circ} \mathrm{C}$ oven to remove most of the solvent. The semidried poly(amic acid) films were further dried in an oven and transformed into polyimides, by the following heating program: $120{ }^{\circ} \mathrm{C}, 160{ }^{\circ} \mathrm{C}, 180{ }^{\circ} \mathrm{C}, 210^{\circ} \mathrm{C}$ and $250{ }^{\circ} \mathrm{C}$ for $1 \mathrm{~h}$ at each temperature. After stripping the films in hot water, the resulting samples were dried at $65{ }^{\circ} \mathrm{C}$ in a vacuum oven for $24 \mathrm{~h}$.

The thermal imidization leads to cross-linked, partially aliphatic polyimide films, since the special structure of the epiclon dianhydride (Scheme 1) $[46,47]$ is different from that of conventional polyimides.

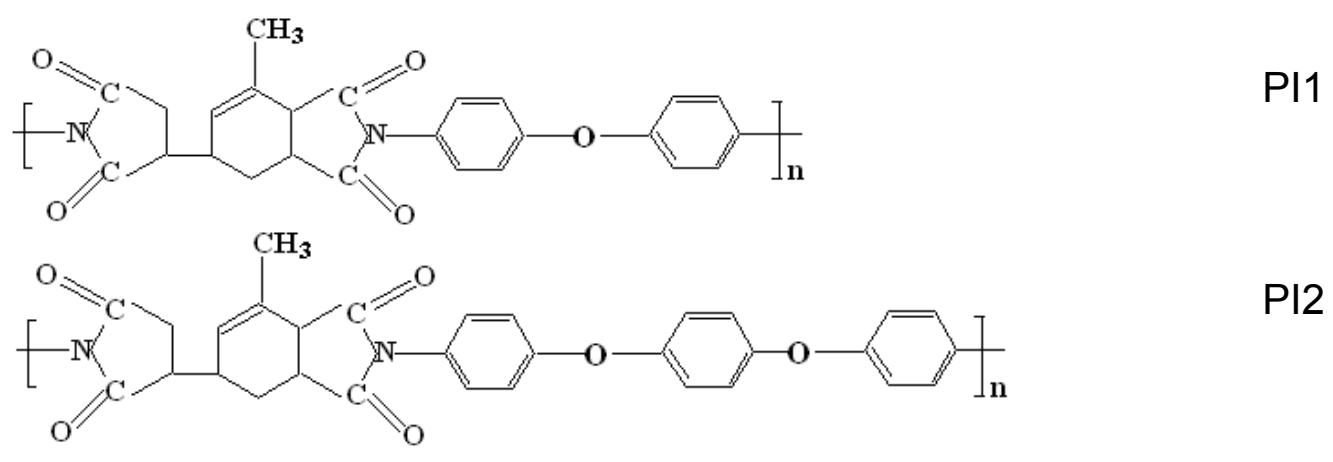

Scheme 1. Structures of the investigated polyimides.

Structures of the polyimides were verified by FTIR spectroscopy. The characteristic absorption bands of the imide ring were observed near $1780(\mathrm{C}=\mathrm{O}$ asymmetric stretching), 1720 ( $\mathrm{C}=\mathrm{O}$ symmetric stretching), 1380 ( $\mathrm{C}-\mathrm{N}$ stretching), 1120 and 740 
$\mathrm{cm}^{-1}$ (imide ring deformation). The aryl ether stretching absorbed near $1240 \mathrm{~cm}^{-1}$. The disappearance of amide and carboxyl absorptions indicates a virtually complete conversion of the poly(amic acid) precursor into the polyimide PI2. The polymer PI1 revealed characteristic absorption bands of the imide ring together with two residual amide absorption bands at $1655 \mathrm{~cm}^{-1}$ (amide 1) and at $1520 \mathrm{~cm}^{-1}$ (amide 2). In this case poly(amic acid) film could not be completely converted into imide.

\section{Contact Angle Measurements}

Both polyimide films thus prepared were subjected to surface analysis. As probe liquids, double-distilled water, 1-bromo-naphthalene and formamide, purchased in the maximum obtainable purity, were used. Uniform drops of the test liquids, with a volume of $1 \mu \mathrm{L}$, were deposited on the film surface, and the contact angles were measured after $30 \mathrm{~s}$ on a video-based optical contact angle measuring device equipped with a Hamilton syringe, in a temperature-controlled environmental chamber. All measurements were performed in the atmosphere, at a temperature of $25{ }^{\circ} \mathrm{C}$. Five repeated measurements of a given contact angle were performed, the errors recorded being within $\pm 3^{\circ}$. The errors can be higher than the values published in literature, due to the problems encountered in obtaining uniform, defectfree films with correct thickness for polyimides [48].

\section{Atomic force microscopy measurements}

The AFM images were taken in air, on a SPM SOLVER Pro-M instrument. A NSG10/Au Silicon tip with a $35 \mathrm{~nm}$ radius of curvature and $255 \mathrm{kHz}$ oscillation mean frequency was used. The apparatus was operated in semi-contact mode, over a $3 \times 3$ $\mu \mathrm{m}$ scan area, 256x256 scan point size images being thus obtained.

\section{Plasma treatment}

The samples were plasma-treated, by exposing the polymer films to low temperature and low pressure glow discharge. Cold air plasma was produced using a $1.3 \mathrm{MHz}$ high frequency system, with $3000 \mathrm{~V} / \mathrm{cm}$ intensity, 0.58 mbarr pressure and $100 \mathrm{~W}$ power, equipped with inner aluminium electrodes. Duration of the plasma treatment was of $10 \mathrm{~min}$, the AFM measurements being performed immediately after it, and also after 10 days.

\section{Ellipsometry measurements}

The refractive index, $n_{2}$, and the extinction coefficient, $k_{2}$, of the polyimide films were evaluated on an EL X-01R ellipsometer, using the monochromatic red light from a He-Ne laser $(\lambda=632.8 \mathrm{~nm})$. The method allows evaluation of these parameters from the correlation among the incidence angle, $\alpha$, amplitude of the reflected and incident electric field ratio, $\Psi$, and their phase difference, $\Delta$, according to Eq. (15).

$$
\tan \Psi \cdot e^{i \Delta}=\rho=\frac{r_{p}}{r_{S}}
$$

where $r_{p}$ and $r_{s}$ are the complex Fresnel reflection coefficients of the sample, and subscripts " $p$ " and " $s$ " refer to the component of the electric field parallel and perpendicular to the incidence plane. These coefficients provide the desired information on the polyimide optical properties. 


\section{Dielectric constant measurements}

The capacitances and I-U characteristics from which the dielectric constants and the electrical resistivities were determined, as well as the electrical conductances were experimentally measured, at room temperature, with an AGILENT 42633 LCR METER apparatus. The films were put into contact with a capacitor at the following frequencies: $1 \mathrm{kHz}, 10 \mathrm{kHz}$ and $100 \mathrm{kHz}$. The capacitor consists of a contact made of silver paste, which covers one side of the film, and is placed on an alumina ceramic wafer, and an aluminum contact deposited through a metallic mask, on the other. A traveling microscope was used for the determination of the capacitor areas $\left(\sim 4 \mathrm{~mm}^{2}\right)$. The thickness of the films was measured by means of a stylus profilometer and found to be $41 \mu$ and $39 \mu$ for PI1 and PI2, respectively. The accuracy of the dielectric constant calculation is assessed for $5 \%$ error of capacitance measurements.

At optical frequencies, the dielectric constants were determined from the refractive indices experimentally evaluated from ellipsometry measurements.

\section{Acknowledgements}

The authors are indebted to the Romanian National Council for Scientific Research in Higher Education (Project TD-547/2007), for financial support.

\section{References}

[1] Ounaies, Z.; Park C.; Wise, K. E.; Siochi, E. J.; Harrison, J. S. Composites Science and Technology 2003, 63, 637.

[2] Mehdipour-Ataei, S.; Saidi, S. e-Polymers 2007, no. 112.

[3] Fukushima, K.; Ikeda, Y.; Hayashi, T.; Kikuchi, N.; Kusano, E.; Kinbara, A. Thin Solid Films 2001, 392, 254.

[4] Muruganand, S.; Narayandass, K.; Mangalaraj, D.; Vijayan, T. M. Polym. Int. 2001, 50, 1089.

[5] Deligoz, H.; Ozgumus, S.; Yalcınyuva, T.; Yıldırım, S.; Deger, D.; Ulutas, K. Polymer 2005, 46, 3720.

[6] Onah, E. J.; Oertel, U.; Froeck, C.; Kratzmuller, T.; Steinert, V.; Bayer, T. Macromol. Mater. Eng. 2002, 287, 412.

[7] Chern, Y. T. Macromolecules 1998, 31, 5837.

[8] Chern, Y. T.; Shiue, H. -C. Macromolecules 1997, 30, 5766.

[9] Maier, G. Prog. Polym. Sci. 2001, 26, 3.

[10] Yamazaki, O.; Yamashita, T.; Horie, K. React. Funct. Polym. 2000, 43, 173.

[11] Hajipour, A. R.; Zahmatkesh, S.; Ruoho, A. E. e-Polymers 2007, no. 88.

[12] de Abajo, J.; de la Campa, J. G. Adv. Polym. Sci . 1999, 140, 23.

[13] Zheng, H. B.; Wang, Z. Y. Macromolecules 2000, 33, 4310.

[14] Spiliopoulos, I. K.; Mikroyannidis, J. A. Macromolecules 1998, 31, 1236.

[15] Liou, G. -S. J. Polym. Sci. Part A 1998, 36, 1937.

[16] Eichstadt, A. E.; Ward, T. C.; Bagwell, M. D.; Farr, I. V. Macromolecules 2002, $35,7561$.

[17] Eichstadt, A. E.; Ward, T. C.; Bagwell, M. D.; Farr, I. V.; Dunson, D. L.; McGrath, J. E. J. Polym. Sci. Part B: Polym. Phys. 2002, 40, 1498.

[18] Matsumoto, T.; Kawabata, S.; Takahashi, R. High Perform. Polym. 2006, 18, 719.

[19] Riyadh, M. A.; Datar, A.; Bhoraskarm, S. V.; Alegaonkar, P. S.; Bhoraskar, V. N. J. Phys. Part D: Appl. Phys. 2006, 39, 4855. 
[20] Wang, H.; Tao, X.; Newton, E. High Perform. Polym. 2002, 14, 271.

[21] Macocinschi, D.; Taranu, A.; Hulubei, C.; Ioan, S. Rev. Roum. Chim. 2006, 51,1001 .

[22] Ioan, S.; Cosutchi, A. I.; Hulubei, C.; Macocinschi, D.; Ioanid, G. Polym. Eng. Sci. 2007, 47, 381.

[23] Cosutchi, A. I.; Hulubei, C.; Ioan, S. J. Optoelectron. Adv. Mater. 2007, 9, 975.

[24] Cosutchi, A. I.; Hulubei, C.; Buda, M.; Botila, T.; loan, S. Rev. Roum. Chim. 2007, 52, 665.

[25] Owens, D. K.; Wendt, R. C. J. Appl. Polym. Sci. 1969, 13, 1741.

[26] Rabel, W. Physikalische Blätter 1977, 33, 151.

[27] Kälble, D. H. J. Adhesion 1969, 1, 102.

[28] van Oss, C. J.; Good, R. J.; Chaudhury, M. K. Langmuir 1988, 4, 884.

[29] van Oss, C. J.; Ju, L.; Chaudhury, M. K.; Good, R. J. Chem. Rev. 1988, 88, 927.

[30] van Oss, C. J. Interfacial Forces in Aqueous Media 1994, Marcel Dekker, New York.

[31] Good, R. J.; van Oss, C. J. Wettability 1992, Chapter 1, Plenum Press, New York.

[32] Wu, W.; Giese, R. F. Jr.; van Oss, C. J. Langmuir 1995, 11, 379.

[33] Della Volpe, C.; Maniglio, D.; Brugnara, M.; Siboni, S.; Morra, M. J. Colloid. Interf. Sci., 2004, 271, 434.

[34] Kwok, D. Y.; Ng, H.; Neumann, A. W. J. Colloid. Interf. Sci. 2000, 225, 323.

[35] Ström, G.; Fredriksson, M.; Stenius, P. J. Colloid. Interf. Sci. 1987, 119, 352.

[36] Rankl, M.; Laib, R.; Seeger, S. Colloids Surf. B: Biointerfaces 2003, 30, 177.

[37] Busscher, H. J.; van Pelt, A. W. J.; de Boer, P.; de Jong, H. P.; Arends, J. Colloids Surf. 1984, 9, 319.

[38] Faibish, R. S.; Yoshida, W.; Cohen, Y. J. Colloid. Interf. Sci. 2002, 256, 341.

[39] Cosutchi, A. I.; Hulubei, C.; Buda, M.; Botila, T.; Ioan, S. e-Polymers 2007, no. 67.

[40] Singh, D. K.; Ray, A. K. J. Appl. Polym. Sci. 1994, 53, 1115.

[41] Eftekhari, A.; St. Clair, A. K.; Stoakley, D. M.; Kuppa, S.; Singh, J. J. J. Polym. Mater. Sci. Eng. 1992, 66, 279.

[42] Hougham, G.; Tesoro, G.; Viehbeck, A. Macromolecules 1996, 29, 3453.

[43] Fragiadakis, D.; Logakis, E.; Pissis, P.; Kramarenko, Y. V.; Shantalii, T. A.; Karpova, I. L.; Dragan, K. S.; Privalko, E. G.; Usenko, A. A.; Privalko, V. P. J. Phys.: Conference Series 2005, 10, 139.

[44] Kim, I. C.; Tak ,T. M. J. Appl. Polym. Sci. 1999, 74, 272.

[45] Mallakpour, S.; Hajipour, A. R.; Zamanlou, M. R. J. Polym. Sci. Part A: Polym. Chem. 2003, 41, 1077.

[46] Hamciuc, E.; Lungu, R.; Hulubei, C.; Bruma, M. J. Macromol. Sci. Pure Appl. Chem. 2006, 43, 247.

[47] Hulubei, C.; Hamciuc, E.; Bruma, M. Rev. Roum. Chim. 2007, 52, 891.

[48] Dunson, L. D. Synthesis and Characterization of Thermosetting Polyimide Oligomers for Microelectronics Packing, PhD Thesis, Virginia, 2000, 189. 